\title{
Technology Interest of Secondary School Students at Five Testing Points over one Complete School Year after Participating at a Student-Centered Learning Program about Bionics
}

\author{
Marth-Busch Michaela and Bogner Franz X. \\ ZMNU (Centre of Math \& Science Education), \\ Department of Biology Education, \\ University of Bayreuth
}

\begin{abstract}
Technology affects our daily lives, although many people do not have any specific knowledge or interest in it. In the learning module fundamentals of technology and biology in different examples of bionics were combined. 324 students took part in a student-centered intervention in a zoo with an affiliated exhibition about bionics. Students were monitored in the interest of technology and its social aspects two weeks before (T0), directly after (T1) and six weeks (T2) after our research-centered learning program with the revised technology questionnaire (Marth \& Bogner, 2018). A sub-sample of 191 students have filled questionnaire at two more testing points at twelve weeks (T3) and one year (T4) after participation. Interest reached its peak immediately after the program and dropped again after six weeks and unfortunately fell back to the level before the intervention. The social aspects sub-scale also showed a peak directly after participation as well as a drop six weeks later. In contrast with the interest sub-scale, the social-sub-scale remained constant at the level after six weeks and even after one year was still higher than before the intervention. The previous interest was shown to be dependent on the scores for knowledge acquisition prior to participation.
\end{abstract}

Keywords: STEM; technology; interest; bionics; long-term study

\section{Introduction}

Technology is omnipresent in daily life (Ardies, De Maeyer, Gijbels, \& van Keulen, 2015). Therefore it is important to know what technology exactly means. A common definition of technology is: "any modification of the natural world done to fulfill human needs or desires" (Ardies, De Maeyer, \& David Gijbels, 2013). But technology is more than that, as Mc Robbie (2000) pointed out using five main dimensions of technology: 1) a human dimension, designed and constructed by inventors 2) a social dimension, used and implemented by society, as well as influenced society's values 3) technology as a process, 
knowledge of and working with materials as well as technology involved in the solution of problems 4) a situated dimension -elaborated with limitations 5) an artifacts dimension involving the development of products.

Although technology affects nearly all categories of life, most people regard it as boring, hard to learn and also often associated with risks (Ardies et al., 2013). Because of this, it is important that even young students come into contact with technology as early as possible. Technical toys at home show a positive influence on technology variables (Ardies et al., 2013). Also, parents have enormous influence through their own experiences, for example, parents with technology occupations exert a positive influence on attitudes and interest in technology (Ardies et al., 2015). School curricula and teachers should prepare children appropriately and sufficiently (ISB, 2004). Therefore it is important that students at the beginning of their technology education make positive experiences, that they are interested in technology and science, and also enjoy learning technology topics during their school time as well as the rest of their lives because initial negative experiences lead to avoiding technology afterward (Akpınar, Yildız, Tatar, \& Ergin, 2009). Therefore, building positive attitudes toward technology is of great importance (Akpinar et al., 2009). Negative experiences often lead to negative attitudes, which are afterward very difficult to change and probably remain for the rest of students' lives (Simpson \& Oliver, 1990). The overall beliefs of students about the utility of science and technology are positive, but general attitudes towards it decrease during school time (George, 2006). Technology education is at the moment more important than ever before, but general views are still negatively (Ardies et al., 2015). This is also shown in a study of Ardies et al., (2013) who described students' interest in technology during a school career and showed that interest in technology decreased from the first to the second level of secondary education, especially for girls.

Integrative STEM education approaches showed positive effects on technology education in high schools (Fan \& Yu, 2017). In the United States, for example, more and more STEM schools have been established to ensure pupils fulfill future job requirements (Eisenhart et al., 2015). Curricular changes in the STEM education sector are omnipresent (Dickerson, Eckhoff, Stewart, Chappell, \& Hathcock, 2014). Innovative technology-driven pedagogical approaches seem to lead to international cooperation with the aim to generate knowledge and new and inspiring ideas in the STEM sector (Kärkkäinen \& Vincent-Lancrin, 2013). Technology education could be a chance to build positive and reduce negative attitudes towards technology (Wolters, 1989). A possibility to overcome the negative attitudes is to train even pre-service teachers to generate positive attitudes as early as possible (Wolters, 1989). Especially primary school teachers have incorrect concepts about technology and its applications, and therefore they have to be supported in technology education (Mc Robbie, 2000). Moreover, secondary school teachers often view technology education as unimportant; and they see in the eyes of their subject and what is the additional benefit for the taught subject specification (Alister \& Carr, 1992). Professional teacher development could help to improve such attitudes, as could the provision of appropriate training material for the students (Alister \& Carr, 1992). Students 
should be taught that technology is a part of everyday life and that it could help them in nearly every area of their lives (Raat, de Klerk Wolters, de Vries, 1989). Teachers could include technology in every subject if there is no separate subject in school: this would improve the technology know-how and skills of students (Wolters, 1989). Technology education should be included in the curricula, integrating content knowledge, teachers' pre-knowledge and educational approaches to teach effectively using the newest technologies (Harris, Mishra, \& Koehler, 2009). A decade ago such an attempt was conducted in the Bavarian syllabus with the introduction of a subject called "Nature and technology"(ISB, 2004). The latest reform was introduced in 2017 when the curriculum was renewed in Bavaria to introduce technology education (ISB, 2017).

Interest in technology is of great importance in our study. Interest is defined "as a content-specific motivational characteristic composed of intrinsic feelingrelated and value-related valences" (Schiefele, 1991). Interest is accordingly dependent on the intrinsic value and feelings of a person. Interest can be influenced and could be increased through motivation as well as through meaningful personal engagement (Renninger, 2015). Interest in tasks could be also increased if the value for usefulness is known even before the task, but those who have low expectations of success do not have an advantage from the utility value (Durik, Shechter, Noh, Rozek, \& Harackiewicz, 2014). That is in line with the findings of Ryan \& Deci (2000) who showed that interest is the most relevant regulatory process of intrinsic motivation. The self-determination theory of Deci \& Ryan (1985) differentiated two types of motivation, namely intrinsic and extrinsic motivation. Intrinsic motivation is related to the inherent will to do something and is not driven by outer circumstances. Extrinsic motivation has to do with goal-orientated tasks that are dedicated and driven from the outside. The first type of motivation exists in every human being, but not every task motivates people intrinsically; it is dependent on the person what does them motivated intrinsically (Ryan \& Deci, 2000). People who have authentic motivation also show more interest in any situation (Ryan \& Deci, 2000). One can enhance intrinsic motivation by using interesting activities, but when an external variable is added, the intrinsic value goes down. For example, when people are rewarded for an interesting activity, intrinsic motivation is lower than when they are not rewarded for the action because they get an external inducement for an interesting duty (Deci, Koestner, \& Ryan, 1999). The more externally regulated and motivated students are, the less interest they show. It is important to raise student's intrinsic as well as extrinsic motivation towards technology, to overcome the decrease of interest, as shown in many studies (Osborne, Simon, \& Collins, 2003; Kiemer, Gröschner, Pehmer, \& Seidel, 2015). Especially the intrinsic factor of interest must be promoted as early as possible to capture interest technology, and hence we tried to enrich our student-centered learning program with a variety of learning materials in order to reach as many students as possible via intrinsic motivation.

Nevertheless, to date, no study exists monitoring interest in technology and its social aspects over the long term. There have been several questionnaires about technology, including interest. In the 1980s the PATT (Pupils Attitudes towards 
Technology) (Raat, \& de Vries, 1986) and the APAT (Attitudes and Perceptions About Technology) measured technology perceptions of students (Rennie \& Treagust, 1989). An improvement in that questionnaire led to Harding \& Rennie (1992) Technology Questionnaire. This Questionnaire was shortened in the study of Marth \& Bogner (2018) and extended to other age-groups. It proved suitable also for freshmen and teachers. To measure these pre-perceptions of interest in technology and the social aspects of technology we use the Technology Questionnaire of Marth \& Bogner (2018) with two sub-scales: Interest in Technology (5 items) and Social Aspects of Technology (5 items). To test whether we could raise interest over a longer time period, we conducted 5 testing points in a single year.

Often Technology and Science are male-led professions and institutions, often resulting in gender differences in the technology area (Akpinar et al., 2009). For example, Marth \& Bogner (2018) reported higher technology interest scores and recognition of more social implications of technology for boys in lower secondary school than girls. This trend has also been detected with freshmen and in-service science teachers. Only the social implications of technology seem similar to teacher cohorts. Often Technology as well as Science, in general, are often dominated by males, so that women often feel themselves in a minority, or even discriminated against (Steele, James, \& Barnett, 2002). Negative attitudes of women are also due to the small chance to combine family and work in the science sector (Frome, Alfeld, Eccles, \& Barber, 2006). This negative trend for female employees is familiar with the entire STEM sector (Science, Technology, Engineering, and Math) (Blickenstaff, 2005). Although many jobs in the STEM sector are available, most are given to male applicants (Dasgupta \& Stout, 2014). Women are often in the minority in the STEM sector in university degrees as well as in permanent jobs (Beede, Julian, \& Langdon, 2011). The gender differences are present in every age and social group and developed already in school, where pupils display negative attitudes (Weinburgh, 1995; Cannon \& Simpson, 1985). This is in line with Weinburgh (2000), who also showed that males have more positive attitudes towards the STEM sector.

\section{Research Goals}

The present study focused on interest in technology as well as social aspects of technology, in the context of a short-time cooperative learning program about bionics at a zoo. The objectives of our study were: (I) to analyze scores on interest and on social aspects of technology (II), to analyze long-term effects over one year, (III) to monitor potential gender differences in technology interest and knowledge acquisition (IV) to examine the relationship between knowledge acquisition and individual technology preferences.

Research Gap

Interest in the technology sector mostly have been observed shortly and not in a long-term investigation. This experiment was conducted in this study. 


\section{Methods}

\section{Bionics Module in the zoo}

The bionics intervention required five complete school lessons in a zoo, where the students worked in different areas including a seminar room as well as areas at the compound (see table 1). All study days were conducted by the same teacher and the same tutor to ensure the similarity of the sessions (Marth \& Bogner, 2017a). At the beginning of the intervention, there was a teacher-guided introductory pre-group phase to ensure a common level of pre-knowledge. This phase included selected issues concerning bionics, biology, and technology. In this phase, students get to know what bionics is and what they will learn during the out-of-school day in the zoo. Afterward, the students are divided into groups and work on their own with hand-on guided learning in these groups for the aquarium and the seminar room module.

The group phase was divided between a seminar room and an aquarium module, where we followed a student-centered learning approach with groups of 3 or 4 students. The seminar room module was held inside a special classroom in the zoo, while the aquarium module was directly at the aquaria in the zoo. These module parts were cooperative learning forms, where the teacher just gave help if it was needed. The group work in the seminar room and the aquarium module was self-explanatory, with hands-on work stations but guided by a workbook, issued to every student at the beginning of the program.

Aquarium module

The main topic was aquatic bionics: dolphins, seals, fish, and manatees were the biology models. Students get to know bionics examples modeled directly from the original object. The self-explanatory station at the aquarium dealt with a variety of bionics examples of the dolphin-like sonar system or the nose of the dolphin, knowledge of which is applied in the tsunami pre-warning system and the bulbous bow of big tankers. The sonar system and the bionics application were compared at an auditory station where students could follow scientists' thoughts and the transfer to technical applications. Another example was the vibrissa of seals, applied in antenna.

\section{Seminar room module}

The second module was conducted in a seminar room module at the zoo. The main topic was the streamlined shape of aquatic animals and their bionics applications in cars or planes. Students performed an experiment with different shapes such as a bowl, a cube or a streamlined shape. Subsequent analyses with an immersion gauge head measured the depth and drew conclusions about streamline shape. Another main topic was the Fin-Ray-effect in the tail fins of fish, applied in picker arms for lamps or eggs. Also, the sharkskin and its technical application in riblet layers were presented in the seminar room. Another station dealt with different famous bionics topics to show the daily applications of bionics.

In the last phase, students repeat all the learned topics in the public exhibition "Bionicum", which is directly affiliated to the zoo. In the exhibition has handson stations, interesting experiments like the hexagonal construction model of a 
honeycomb, which is inserted I washing machines. The students could test the stability of different metal forms, concluding that the hexagonal form is the best. They could also watch a film about the honey bee and look inside a beehive. The human being is also a bionics example shown in a robot, which could dance, walk or speak to visitors.

Design

In the Bionics module, 324 Bavarian 6th graders (age $M=12.2$ years, 189 girls, 135 boys) participated in the intervention in the zoo. We have 6 schools participating in the out-of-school project with all their 6th graders. Participants first completed a survey two weeks before the intervention, including the technology questionnaire and a pre-knowledge test (T0). The technology questionnaire, which was confirmed by Marth \& Bogner (2018) had two subscales: interest (5items) and social implication (5items).

Table 1: Relevance of objectives of teaching subjects at the university

\begin{tabular}{|c|c|c|c|}
\hline & phase of teaching & description & students activity \\
\hline \multirow{4}{*}{$\begin{array}{l}\text { Com- } \\
\text { bination }\end{array}$} & pre-group phase & introduction to bionics & $\begin{array}{l}\text { teacher-guided } \\
\text { introductory phase }\end{array}$ \\
\hline & $\begin{array}{l}\text { module } 1 \\
\text { (seminar room } \\
\text { module) }\end{array}$ & seminar room activity & $\begin{array}{l}\text { hands-on guided } \\
\text { learning }\end{array}$ \\
\hline & $\begin{array}{l}\text { module } 2 \\
\text { (aquarium module) }\end{array}$ & $\begin{array}{l}\text { Learning directly on } \\
\text { the living animal }\end{array}$ & $\begin{array}{l}\text { hands-on guided } \\
\text { learning }\end{array}$ \\
\hline & post-group phase & $\begin{array}{l}\text { exhibition } \\
\text { „BIONICUM“ }\end{array}$ & $\begin{array}{l}\text { example of informal } \\
\text { learning }\end{array}$ \\
\hline
\end{tabular}

At the end of the intervention day, students completed a post-test (T1), and, after six weeks, a retention test (T2). A subsample $(n=183)$ completed two more surveys at testing points after 12 weeks (T3) and 1 year (T4) (Figure 1)The knowledge test consisted of 30 items dealing with the topics of the day, and general questions about bionics, technology, and biology. All students filled to all testing points both scales (technology questionnaire and knowledge test). 


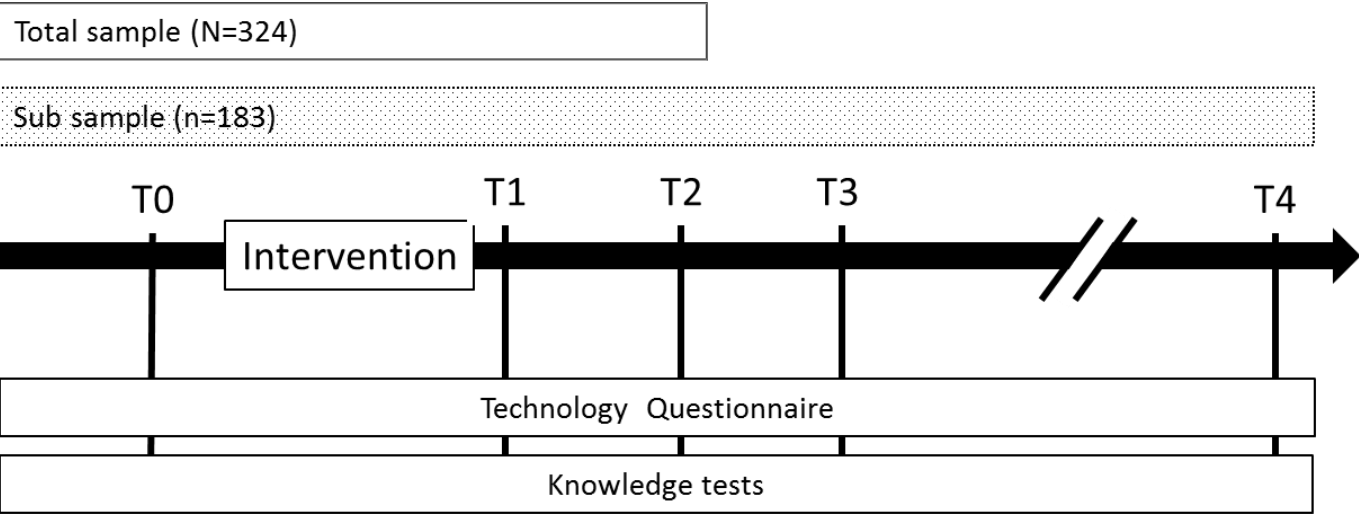

Figure 1: Schedule of questionnaire implementation

\section{Statistical analysis}

For the statistical analysis, the updated SPSS 23 was used. Accepting the central limit theorem, we used parametric tests (Field, 2013). We analyzed the Technology Questionnaire using mean scores. We used repeated measurement ANOVAs for three as well as for five measurement points each, for interest and for social aspects. For the pairwise comparisons at the various testing points, we used post-hoc testing with a Bonferroni correction. For the analysis of the gender differences, we used t-tests. The Pearson correlation coefficient shows the relationship of knowledge levels with the TQ subscale mean scores. Analysis of knowledge was based on sum-scores, with correct answers labeled "1", incorrect ones " 0 ".

\section{Results}

Change in interest and social aspects at three testing points

The change in interest and social aspects seems reasonable (see figure 2). The lowest scores are at the pre- level, followed by an increase directly after participation and a decrease 6 weeks later, which is however higher than before intervention:

Mean scores (M) differed significantly for the interest sub-scale: between the 3 different measurement points $\mathrm{T} 0(\mathrm{M}=2,12 \mathrm{SD}=1,026), \mathrm{T} 1(\mathrm{M}=2,98 \mathrm{SD}=, 99)$ and $\mathrm{T} 2$ $(\mathrm{M}=2,45 \mathrm{SD}=1,20)$ (Figure 2) $(\mathrm{F}(2,61,669)=84,600, \mathrm{p}<.001)$ for the total sample $(n=324)$. The pairwise comparison using post-hoc test and Bonferroni correction showed an increase in technology interest, both short-term (T0 to T1; $\mathrm{p}<.001$ ) and medium-term (T0 to T2; $\mathrm{p}<.001$ ).

The sub-scale social aspects differed significantly for mean scores (M):between the 3 different measurement points T0 $(\mathrm{M}=1,67 \mathrm{SD}=1,05)$, T1 $(\mathrm{M}=2,85 \mathrm{SD}=, 74)$ and T2 $(\mathrm{M}=2,38 \mathrm{SD}=, 975)$ (Figure 2) $(\mathrm{F}(1,902,119,821)=163,649, \mathrm{p}<.001)$ for the total sample $(\mathrm{n}=324)$. For ANOVA of the sub-scale Social Aspects Mauchly`s test showed a violation of the assumption of sphericity: chi-square $(2)=16,968$, therefore, degrees of freedom were corrected by using Huynh-Feldt estimates of sphericity .957. The pairwise comparison using Bonferroni post-hoc tests showed an increase of technology interest, both short-term (T0 to T1; $\mathrm{p}<.001$ ) and medium-term (T0 to T2; $\mathrm{p}<.001)$. 


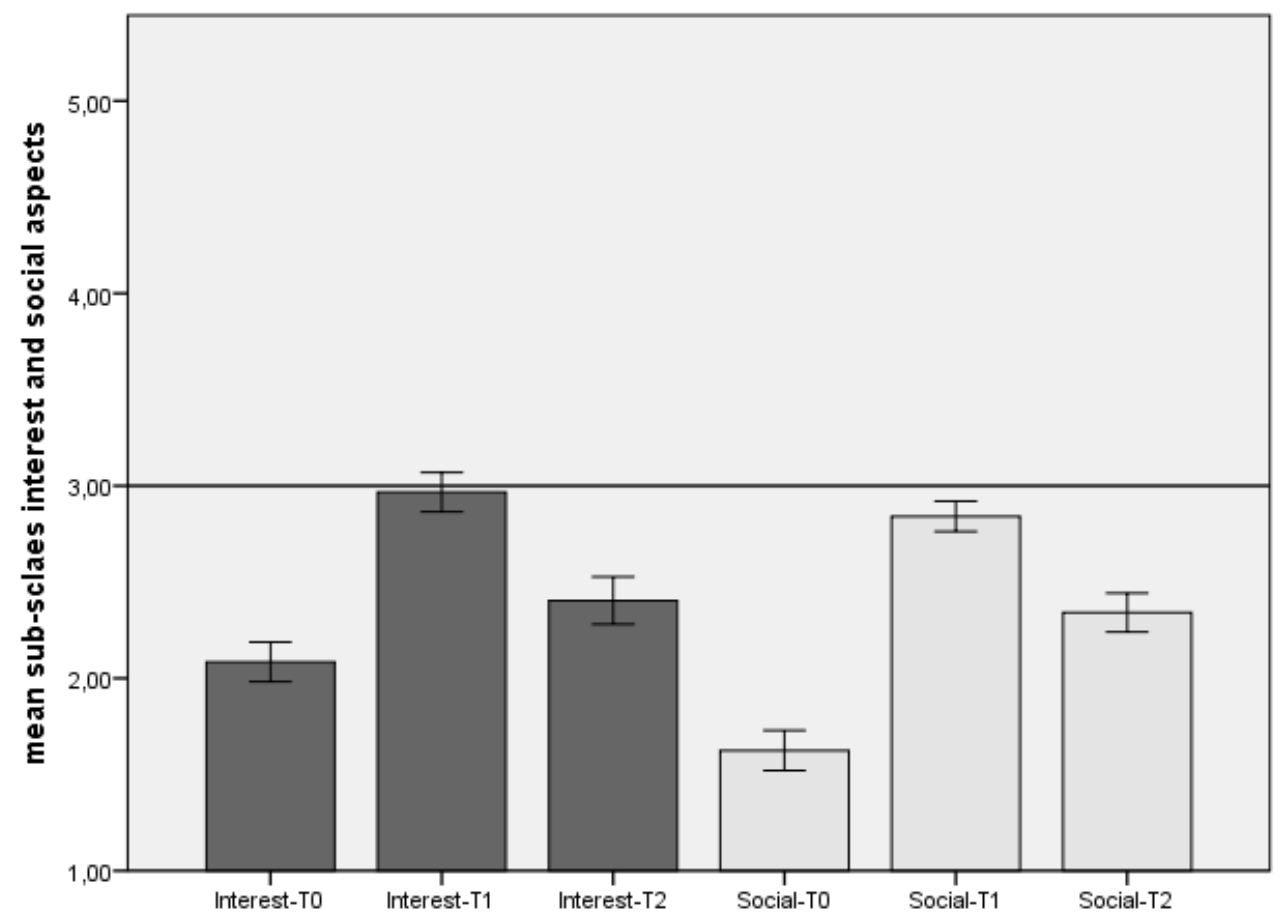

Figure 2: Mean scores of the sub-scales interest and social aspects at 3 different testing points; Bars are $95 \%$ confidence intervals.

Change in interest and social aspects at five testing points

A sub-sample of $n=183$ completed the Technology Questionnaire 5 times within one year (Figure 3). In the subscale Interest, the lowest scores are again at the pre-level, followed by an increase directly after participation and a decrease six weeks later, even back to the level before the intervention. The following retention scores after twelve weeks and one year after participation showed the same trend. The repeated measurement ANOVA showed significant differences in the sub-scale interest $(\mathrm{F}(3,220,26,967)=21,849, \mathrm{p}<.001)$. For the total module chi-square (9)=83,101, Mauchly`s test showed a violation of the assumption of sphericity, therefore degrees of freedom were corrected by using Huynh-Feldt estimates of sphericity .805.

The mean scores increased from T0 to T1, dropped at T2, T3, and T4 (Figure 3a). The post-hoc pair-wise comparison with the Bonferroni correction showed similar results. Interest increases only in the short-term (TO to T1; $<<.001$ ) and showed after six weeks, twelve weeks and one year the same level of interest as before the intervention ( $\mathrm{T} 0$ to $\mathrm{T} 2 ; \mathrm{p}=.053)$, ( $\mathrm{T} 0$ to $\mathrm{T} 3 ; \mathrm{p}=1.00)$ ( $\mathrm{T} 0$ to $\mathrm{T} 4 ; \mathrm{p}=1.00)$.

In the subscale social the lowest scores are again $\mathrm{T}$ the pre-level, followed by an increase directly after the participation and a decrease six weeks later which is however higher than before the intervention. The following retention scores after twelve weeks and one year after participation showed the same trend as after 6 weeks (see figure 3A). The repeated measurement ANOVA showed significant differences in the sub-scale social aspects $(\mathrm{F}(3,515 ; 35,162)=41,426$, $\mathrm{p}<.001)$. For the chi-square $(9)=50,552$ Mauchly`s test showed a violation of the 
assumption of sphericity, therefore degrees of freedom were corrected by using Huynh-Feldt estimates of sphericity .879 .

Table 2: Mean value and standard deviation of the items in the different sub-scales

\begin{tabular}{lcc|cccc|cc|cc}
\hline Module & $T 0$ & $S D$ & $T 1$ & $S D$ & $T 2$ & $S D$ & $T 3$ & $S D$ & $T 4$ & $S D$ \\
\hline Interest & 2.24 & 1.00 & 3.08 & .97 & 2.50 & 1.16 & 2.32 & 1.29 & 2.30 & 1.17 \\
\hline $\begin{array}{l}\text { Social } \\
\text { aspects }\end{array}$ & 1.69 & .94 & 2.83 & .76 & 2.36 & .99 & 2.32 & .98 & 2.13 & 1.04 \\
\hline
\end{tabular}

The social aspects mean scores increased from $\mathrm{T} 0$ to $\mathrm{T} 1$, dropped at $\mathrm{T} 2$ and remained constant at T3 and T4 (Figure 3B, Table 2). The post-hoc pair-wise comparison with the Bonferroni correction showed similar results. Social aspects increase short-term ( $\mathrm{TO}$ to $\mathrm{T} 1 ; \mathrm{p}<.001$, mid-term ( $\mathrm{T} 0$ to $\mathrm{T} 2 ; \mathrm{p}<.001$ ), mid-midterm (T0 to T3; $\mathrm{p}<.001$ ) and also in the long-term (T0 to T4; $\mathrm{p}<.001$ ). Social aspects dropped from T1 to T2, T3 and T4 (T1 to T2; $<<.001, \mathrm{~T} 1$ to T3; $<<.001, \mathrm{~T} 1$ to $\mathrm{T} 4 ; \mathrm{p}<.001)$. The social aspects mean score remained constant after $\mathrm{T} 2$ and showed no differences to T3 and T4 (T2 to T3; $\mathrm{p}=1.00$, T2 to T3; $\mathrm{p}=.295$, T3 to T4; $\mathrm{p}=.791$ ) and seemed to remain constant for a one year time period (T4).
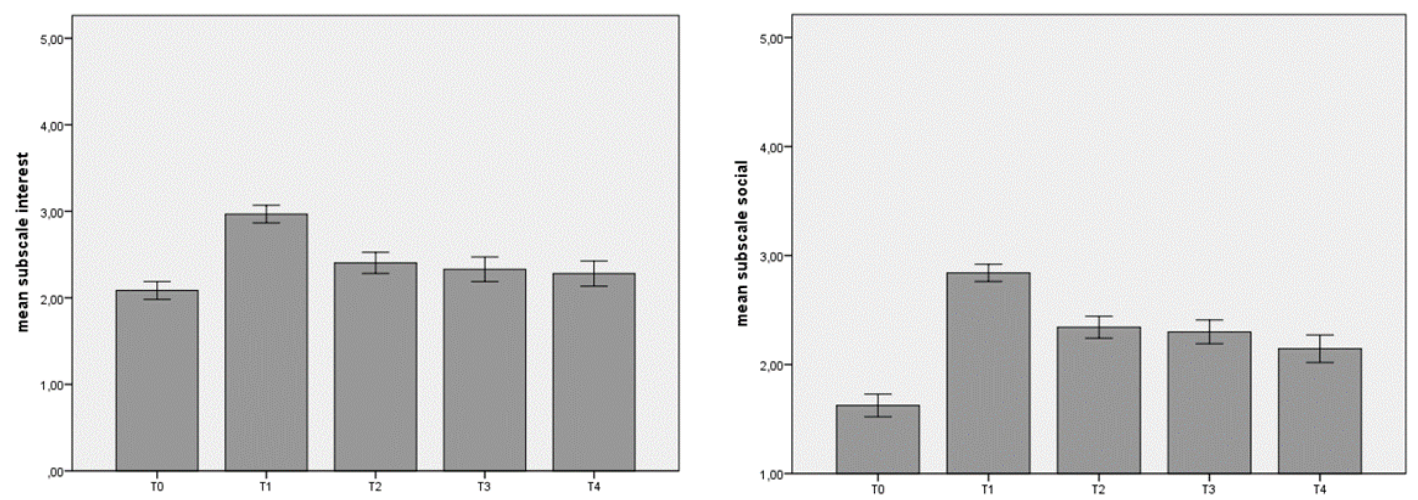

Figure 3A\&B: Mean scores of the sub-scales interest (A) and social aspects (B) at 5 different testing points; Bars are $95 \%$ confidence intervals.

Gender distinction Technology Questionnaire

Female and male participants did not differ significantly at any testing point in both sub-scales social aspects as well as interest in technology (see table 3). 
Table 3: Mean value and standard deviation of the items in the different sub-scales

\begin{tabular}{|c|c|c|c|c|c|}
\hline & T1 & $\mathrm{T} 2$ & T3 & T4 & $\mathrm{T} 5$ \\
\hline & \multicolumn{5}{|c|}{$T Q$ (sub-scale interest) } \\
\hline Female & $2,05 \pm 1,02$ & $2.98 \pm .94$ & $2.40 \pm 1.12$ & $2.41 \pm 1.31$ & $2.33 \pm 1.17$ \\
\hline Male & $2,11 \pm 1,03$ & $2.96 \pm 1.04$ & $2.44 \pm 1.24$ & $2.27 \pm 1.28$ & $2.26 \pm 1.16$ \\
\hline \multirow[t]{2}{*}{ t-test, Sig. } & n.s. & n.s. & n.s. & n.s. & n.s. \\
\hline & \multicolumn{5}{|c|}{$T Q$ (sub-scale social) } \\
\hline Female & $1.64 \pm 1.15$ & $2.84 \pm .73$ & $2.23 \pm .89$ & $2.36 \pm .88$ & $2.11 \pm .96$ \\
\hline Male & $1.61 \pm .94$ & $2.84 \pm .78$ & $2.44 \pm 1.04$ & $2.26 \pm 1.06$ & $2.13 \pm 1.07$ \\
\hline t-test, Sig. & n.s. & n.s. & n.s. & n.s. & n.s. \\
\hline
\end{tabular}

A relationship between scores on the Technology Questionnaire and preknowledge was observed and showed significant correlations at all measurement points and with both sub-scales social aspects and interest of technology (see table 4).

Table 4: Correlations between sub-scales of TQ and knowledge

\begin{tabular}{ll|l|l|l|l}
\hline & T1 & T2 & T3 & T4 & T5 \\
\hline \multicolumn{5}{c}{ Correlation TQ (sub-scale interest) } \\
\hline $\begin{array}{l}\text { Correlation } \\
\text { coefficient }\end{array}$ & $.576^{* * *}$ & $.674^{* * *}$ & $.697^{* * *}$ & $.763^{* * *}$ & .029 \\
\hline \begin{tabular}{l} 
Sig. \\
\cline { 2 - 6 }
\end{tabular} & $<0.001$ & $<0.001$ & $<0.001$ & $<0.001$ & n.s. \\
\hline
\end{tabular}

Correlation TQ (sub-scale social implication)

\begin{tabular}{ll|l|l|l|l}
\hline $\begin{array}{l}\text { Correlation } \\
\text { coefficient }\end{array}$ & $.496^{* * *}$ & $.589^{* * *}$ & $.653^{* * *}$ & $.667^{* * *}$ & .080 \\
\cline { 2 - 6 } Sig. & $<0.001$ & $<0.001$ & $<0.001$ & $<0.001$ & n.s. \\
\hline
\end{tabular}

\section{Discussion}

The bionics module raised interest and also scores on social aspects of technology significantly. Students showed more interest in technology and higher scores on social aspects of technology directly after the intervention. There are different explanations for the growth in interest and social aspects of technology from the students who are participated: 
Reasons for interest and social aspects enhancement

Cooperative learning could be mentioned as one reason for interest and social aspects growth in our study. The students worked in groups of 3-or 4 in a hands-on cooperative learning approach. Cooperative learning seems to be more than putting some students together for working on a special topic. Cooperative learning is described through the personality interaction of students as well as through the responsibility of each student for the output of the group and also the effectiveness of the group (Johnson \& Johnson, 1994, S.32). Cooperative learning classes often show more achievement as in traditional learning approaches, as shown by Bertucci, Conte, Johnson, \& Johnson (2010). They also indicated a higher value of peer supporting than individual learning, especially social self-esteem seems to be higher (Bertucci, Conte, Johnson, \& Johnson, 2010). This result is also shown in a meta-analysis of 65 studies with cooperative learning approaches, which showed positive effects on attitudes and learning (Kyndt et al., 2013). Studies of cooperative learning in a zoo are rare in the literature, but Sattler \& Bogner (2016) reported a study on marine mammals in the zoo which demonstrated an increase in knowledge after participation. The cooperative learning approach in combination with the zoo offers a possibility to increase interest and social influences in the belonging of technology. Lord (2001) showed that scientific thinking, as well as social skills, are improved during cooperative learning forms. Our hands-on learning seems to increase interest and motivation for technology. These results are also shown in a study by Poudel et al. (2005), who also showed that hands-on learning promotes interest and motivation. Another reason for interest increase could be the out-ofschool environment. Our intervention was in a zoo with an affiliated exhibition, where the students learned bionics directly on the living animal and could replicate everything in the exhibition with interesting experiments and hands-on materials. Out-of-school activities, such as visiting zoos, science centers or botanical gardens have been shown to be useful for learners Sattler \& Bogner (2016). For that purpose, good teacher preparation is obligatory (Davidson, Passmore, \& Anderson, 2010), because there are many influences such as preknowledge levels, previous experiences in out-of-school learning environments, cognitive loads of the students as well as a novelty effect that could disturb the instruction (McClafferty \& Rennie, 1995). Outreach learning often generates knowledge and interest gains (Langheinrich \& Bogner, 2016), so we decided to combine an out-of school learning approach with hands-on experiences in the zoo. In our study we conducted a pre-group phase to insure the same preknowledge of all students. With good preparation it is possible to raise interest as well as social aspects of technology.

\section{Attitudes forming experiences}

In science and technology education it is of great importance from the beginning that students enjoy positive experiences and also build positive attitudes, so that they may later be successful in the scientific sector (Akpinar et al., 2009). Technology and technological education till have a negative image even though the technical sector is increasingly important in the daily life of students (Ardies et al., 2015). Ardies et al. (2013) pointed out that the interest of technology decreases from the first to the secondary level of school. Speering \& Rennie 
(1996) also showed that attitudes to technology grow more negative during a school career, although technology influences students' life. For example, social media influence is omnipresent (O'Keeffe \& Clarke-Pearson, 2011). Technology reaches all areas of life and influences students as well as adults. This trend is recognized even by policymakers but society still has a negative image of technology (Ardies et al., 2013). Hence, it is important that students are come into contact with technology and acquire more positive attitudes than previous generations. Attitudes of peers, as well as their self-concept influence the students (George, 2000). It is important for teachers to know their students' attitudes towards science and technology, in order to adapt teaching methods and educational procedures (Lovelace \& Brickman, 2013). A teacher's knowledge also influences attitudes (Rohaan, Taconis, \& Jochems, 2010). Educational initiatives should always be aware of attitudes in order to foster interest.

Long-term interest gain persisting over one year

Our study yielded a long term effect on social aspects of technology, but we couldn't conclude that this effect derived from our intervention because in a school year many other topics as well as out of school events could have happened, which we couldn't influence. But we can say that after one year the social dimensions of students in the technology area are higher than one year before. We are able to assume that our intervention influenced the high scores in the social sector. On the other hand, interest was raised only immediately after the intervention. Six weeks later as well as one year later the interest was at the level it had before the intervention. This result finds support in other studies, where interest is hard to influence because it is a fundamental part of the personality (Ryan \& Deci, 2000). Interest is dependent on intrinsic values as well as on the feelings of persons and not so easy to change has. It is much easier to stimulate interest briefly than to change intrinsic motivation and interests. This is included in the self-determination theory of Deci \& Ryan (1985), who differentiate between intrinsic and extrinsic motivation: On the one hand doing something on the basis of inherent will (intrinsic), or on the other doing something which is mostly driven by outer circumstances (extrinsic). The first kind of motivation exists in every human, but not in the same areas (Ryan \& Deci, 2000). So it could be that less interested students also showed less intrinsic motivation for our science and technology-related intervention about bionics.

\section{Long-term effect in questionnaires}

Most questionnaires yield similar scores for different times of testing. The questionnaire (MEV (Major Environmental Values) yields persisting structures (Bogner \& Wiseman, 1999). Other studies, using mostly knowledge questionnaires, report an increase in knowledge scores. For example, Schmid \& Bogner (2015) examined in an inquiry-based science education learning module about hearing and sound for 9th graders, observed an increase in knowledge directly after participation as well as a long-term effect twelve weeks after the intervention. Another example, a study on bionics in a zoo, showed a knowledge gain persisting even after one year (Marth \& Bogner, 2017a). Another study about bird species in the zoo also showed long term effects after nine weeks (Randler, Baumgärtner, Eisele, \& Kienzle, 2007). The control group visited the 
zoo with no intervention, but also showed greater interest than the treatment group. Fančovičová \& Prokop (2011) also demonstrated a knowledge increase after three months compared to a control group.

Most studies working only with shorter pre- and post-test designs, because of the logistical problems longer testing periods. We measured at 5 testing points even one year after the intervention to see the long term effect of our learning intervention and found significant differences. The results followed the same pattern as in the studies with knowledge questionnaires: a peak directly after participation, followed by a long-time decrease, still above the pre-testing level.

\section{Gender differences}

Gender differences are often seen in the STEM (science, technology, engineering, and math) sector (Beede et al., 2011). These findings are also seen in the study of Marth \& Bogner (2018), where secondary school students showed gender differences in technology interest as well as in the social implications of technology. This was also shown for two different age groups, namely freshmen and a teacher's cohort (Marth \& Bogner, 2018). Only the social aspects of the teacher's cohort showed no change. This trend is often seen in school, where attitudes of students are formed (Cannon \& Simpson, 1985). Other studies support our findings of no gender differences with regard to technology, like Zeyer \& Wolf (2010) or Zeyer (2010), who have shown that cognitive style is more important for learning gender. Primary school children showed nearly the same confidence in math and science, whereas middle school students already show gender differences (Wigfield, 1996). This also supports our findings, as our students are in the transition phase between primary and secondary school. It could be that gender differences are not yet established. Hence it is important to begin technology and science intervention even in school as early as possible to reduce negative images.

Bionics as a link between technology interest and knowledge

Bionics is one of the newest and most innovative research fields of the last decade. Bionics improves technical applications from the science view and finds appropriate solutions for technical problems and gives many examples of how nature could act as a model for technical problems (Nachtigall \& Wisser, 2013). Neurohr \& Dragomirescu (2007) have shown that bionics have the potential to foster interest and generate also knowledge. In our out-of-school day in the zoo, bionics should be the link between living animals and technical applications, to create interest and also enrich the knowledge of bionics phenomena. Technology preferences even before the intervention showed high scores for knowledge in our study. Knowledge and interest in technology are cognate, and high scores in interest in technology, as well as social aspects of technology, lead to high knowledge scores. So it is important that interested students should be motivated towards still more interest, while the uninterested should be more motivated from the beginning. Bionics is only an example to foster interest in the STEM sector, for a longer time impact such days need to be repeated, and integrated into interdisciplinary learning in the daily school routine. 


\section{Conclusion}

Relating bionics, cooperative learning form, the hands-on station, and the outreach area may support social aspects of technology (Marth \& Bogner, 2017b). The usual logistics problems make testing beyond a year's schedules difficult so that any study of long-term interest needs to demonstrate memory retention after a long time span. In our case, we were able to foster interest shortly after the intervention; for a persisting change in interest, there should be more approaches like the bionics module in the zoo. If you could catch the interest and social aspects of technology at an early stage, young people could be interested perhaps for a lifetime. Therefore, any barriers against such interventions should be conquered to bring more students in the STEM sector (Dasgupta \& Stout, 2014). The STEM sector is a big chance for the next generations to make the world a better place to live in and be prepared for the requirements of the next years. One major goal is also to connect the science fields with the technology fields, to get the best out of collaboration. In addition, these fields have to be brought in school to raise the motivation and interest of young students.

\section{Compliances with the Ethical Standards}

Conflict of Interest: The authors declare that they have no conflict of interest.

The article is the authors' original work, hasn't received prior publication and isn't under consideration for publication elsewhere.

Research involving Human Participants but the ethical standards are followed. The Permission Note has been received to use any material in the manuscript such as figures etc. which isn't original content.

\section{Acknowledgments}

We are grateful to the „BIONICUM for assistance as we are to all schools, teachers, and students for participation. Similarly, we thank the Bavarian Ministry of Education for permitting the study within schools (X.7BO4106/453/9, 03.02.2015). The paper is based on the dissertation thesis of Michaela Marth (https://epub.unibayreuth.de/3532/5/Regenschirm\%208.12.2017\%20Abgabe\%20Final\%20ohne\% 20unterschrift.pdf).

\section{Funding Statement}

Financial support was granted by the CREATIONS Project (European Union Grant Agreement, [No. 665917]), by the OSOS Project (European Union Grant Agreement, [No. 741572 ]), by the University of Bayreuth as well as by the LfU (Landesamt für Umwelt).

\section{References}

Akpınar, E., Yıldız, E., Tatar, N., \& Ergin, Ö. (2009). Students' attitudes toward science and technology: an investigation of gender, grade level, and academic achievement. Procedia - Social and Behavioral Sciences, 1(1), 2804-2808. https:/ / doi.org/10.1016/j.sbspro.2009.01.498

Alister, J., \& Carr, M. (1992). Teachers' perceptions of technology education: Implications 
for curriculum innovation. Research in Science Education, 22(1), 230-239.

Ardies, J., De Maeyer, S., \& David Gijbels. (2013). Reconstructing the Pupils Attitude Towards Technology-survey. Design and Technology Education: An International Journal, 18(2006), 8-19.

Ardies, J., De Maeyer, S., Gijbels, D., \& van Keulen, H. (2015). Students attitudes towards technology. International Journal of Technology and Design Education, 25(1), 43-65. https://doi.org/10.1007/s10798-014-9268-x

Beede, D., Julian, T., \& Langdon, D. (2011). Women in STEM : A Gender Gap to Innovation. U.S. Department of Commerce, Economics and Statistics Administration, 1-11. https://doi.org/10.2139/ssrn.1964782

Bertucci, A., Conte, S., Johnson, D. W., \& Johnson, R. T. (2010). The impact of size of cooperative group on achievement, social support, and self-esteem. The Journal of General Psychology, 137(3), 256-272.

https:// doi.org/10.1080/00221309.2010.484448

Blickenstaff, J. C. (2005). Women and science careers: leaky pipeline or gender filter? Gender and Education, 17(4), 369-386. https://doi.org/10.1080/09540250500145072

Bogner, F. X., \& Wiseman, M. (1999). Toward Measuring Adolescent Environmental Perception. European Psychologist, 4(3), 139-151. https://doi.org/10.1027//10169040.4.3.139

Cannon, R. K., \& Simpson, R. D. (1985). Relationships among attitude, motivation, and achievement of ability grouped, seventh-grade, life science students. Science Education, 69(2), 121-138. https://doi.org/10.1002/sce.3730690203

Dasgupta, N., \& Stout, J. G. (2014). Girls and Women in Science, Technology, Engineering, and Mathematics: STEMing the Tide and Broadening Participation in STEM Careers. Policy Insights from the Behavioral and Brain Sciences, 1(1), 21-29. https:// doi.org/10.1177/2372732214549471

Davidson, S. K., Passmore, C., \& Anderson, D. (2010). Learning on zoo field trips: The interaction of the agendas and practices of students, teachers, and zoo educators. Science Education, 94(1), 122-141. https://doi.org/10.1002/sce.20356

Deci, E L, Koestner, R., \& Ryan, R. M. (1999). A meta-analytic review of experiments examining the effects of extrinsic rewards on intrinsic motivation. Psychological Bulletin, 125(6), 627-668; discussion 692-700. https:/ / doi.org/10.1037/00332909.125.6.627

Deci, Edward L., \& Ryan, R. M. (1985). Intrinsic motivation and self-determination in human behavior. Journal of Chemical Information and Modeling, 53. https://doi.org/10.1017/CBO9781107415324.004

Dickerson, D. L., Eckhoff, A., Stewart, C. O., Chappell, S., \& Hathcock, S. (2014). The Examination of a Pullout STEM Program for Urban Upper Elementary Students. Research in Science Education. https://doi.org/10.1007/s11165-013-9387-5

Durik, A. M., Shechter, O. G., Noh, M., Rozek, C. S., \& Harackiewicz, J. M. (2014). What if I can't? Success expectancies moderate the effects of utility value information on situational interest and performance. Motivation and Emotion, 39(1), 104-118. https:// doi.org/10.1007/s11031-014-9419-0

Eisenhart, M., Weis, L., Allen, C. D., Cipollone, K., Stich, A., \& Dominguez, R. (2015). High school opportunities for STEM: Comparing inclusive STEM-focused and comprehensive high schools in two US cities. Journal of Research in Science Teaching. https://doi.org/10.1002/tea.21213

Fan, S. C., \& Yu, K. C. (2017). How an integrative STEM curriculum can benefit students in engineering design practices. International Journal of Technology and Design Education, 27(1), 107-129. https://doi.org/10.1007/s10798-015-9328-x 
Fančovičová, J., \& Prokop, P. (2011). Plants have a chance: outdoor educational programmes alter students' knowledge and attitudes towards plants. Environmental Education Research, 17(4), 537-551. https://doi.org/10.1080/13504622.2010.545874

Field, A. (2013). Andy Field - Discovering Statistics Using SPSS. (M. Carmichael, Ed.) (4th ed.). London: Sage Publications. https://doi.org/10.1111/j.13652648.2007.04270_1.x

Frome, P. M., Alfeld, C. J., Eccles, J. S., \& Barber, B. L. (2006). Why don't they want a male-dominated job? An investigation of young women who changed their occupational aspirations. Educational Research and Evaluation, 12(4), 359-372. https:// doi.org/10.1080/13803610600765786

George, R. (2000). Measuring Change in Students' Attitudes Toward Science Over Time: An Application of Latent Variable Growth Modeling. Journal of Science Education and Technology, 9(3), 213-225. https://doi.org/10.1023/A:1009491500456

George, R. (2006). A Cross-domain Analysis of Change in Students' Attitudes toward Science and Attitudes about the Utility of Science. International Journal of Science Education, 28(6), 571-589. https:// doi.org/10.1080/09500690500338755

Harding, J., \& Rennie, L. J. (1992). What research says to the science and mathematic teachers. Technology Education in Science and Mathematics (Vol. 10). Perth.

Harris, J., Mishra, P., \& Koehler, M. (2009). Teachers' technological pedagogical content knowledge and learning activity types: Curriculum-based technology integration refrained. Journal of Research on Technology in Education. https:// doi.org/10.1080/15391523.2009.10782536

Institute ISB. (2004). Curriculum 6th grade. Retrieved from https://www.isb.bayern.de/gymnasium/lehrplan/gymnasium/fachprofilebene-2/natur-und-technik-/325/

Institute ISB. (2017). Lehrplan PLUS. Retrieved from https://www.lehrplanplus.bayern.de/seite/lehrplanplus

Johnson, R. T., \& Johnson, D. W. (1994). An overview of cooperative learning. Creativity and Collaborative Learning: A Practical Guide to Empowering Students and Teachers, 31-44. https:// doi.org/10.1007/BF00962280

Kärkkäinen, K., \& Vincent-Lancrin, S. (2013). Sparking Innovation in STEM Education with Technology and Collaboration. A Case Study of the HP Catalyst Initiative. OECD Education Working Papers. https:// doi.org/10.1787/5k480sj9k442-en

Kiemer, K., Gröschner, A., Pehmer, A. K., \& Seidel, T. (2015). Effects of a classroom discourse intervention on teachers' practice and students' motivation to learn mathematics and science. Learning and Instruction, 35, 94-103. https:// doi.org/10.1016/j.learninstruc.2014.10.003

Kyndt, E., Raes, E., Lismont, B., Timmers, F., Cascallar, E., \& Dochy, F. (2013). A metaanalysis of the effects of face-to-face cooperative learning. Do recent studies falsify or verify earlier findings? Educational Research Review, 10, 133-149. https:// doi.org/10.1016/j.edurev.2013.02.002

Langheinrich, J., \& Bogner, F. X. (2016). Computer-related self-concept: The impact on cognitive achievement. Studies in Educational Evaluation, 50, 46-52. https:// doi.org/10.1016/j.stueduc.2016.06.003

Lord, T. R. (2001). 101 Reasons for Using Cooperative Learning in Biology Teaching. The American Biology Teacher, 63(1), 30-38. https://doi.org/10.1662/00027685(2001)063[0030:RFUCLI]2.0.CO;2

Lovelace, M., \& Brickman, P. (2013). Best practices for measuring students' attitudes toward learning science. CBE Life Sciences Education, 12(4), 606-617. https://doi.org/10.1187/cbe.12-11-0197 
Marth, M., \& Bogner, F. X. (2017a). Does the issue of bionics within a student-centered module generate long-term knowledge? Studies in Educational Evaluation, 55(September), 117-124. https://doi.org/10.1016/j.stueduc.2017.09.001

Marth, M., \& Bogner, F. X. (2017b). How a Hands-on BIONICS Lesson May Intervene with Science Motivation and Technology Interest. International Journal of Learning, Teaching and Educational Research, 16(5), 72-89.

Marth, M., \& Bogner, F. X. (2018). Monitoring a gender gap in interest and social aspects of technology in different age groups. International Journal of Technology and Design Education. https:/ / doi.org/10.1007/s10798-018-9447-2

Mc Robbie, J. C. (2000). Preservice primary teachers\&\#039; thinking about technology and technology education. International Journal of Technology and Design Education, 10(d), 81-101.

McClafferty, T., \& Rennie, L. (1995). Using visits to interactive science and technology centres, museums, aquaria and zoos to promoter learning in science. Journal of Science Teacher Education., 6(4), 175-185.

Nachtigall, W., \& Wisser, A. (2013). Bionik in Beispielen: 250 illustrierte Ansätze. SpringerVerlag. Berlin, Heidelberg: Springer Verlag.

Neurohr, R., \& Dragomirescu, C. (2007). Bionics in Engineering-Defining new Goals in Engineering Education at "Politehnica" University of Bucharest. Conference on Engineering Education, 3-6. Retrieved from http://ineer.org/Events/ICEE2007/papers/571.pdf

O'Keeffe, G. S., \& Clarke-Pearson, K. (2011). The Impact of Social Media on Children, Adolescents, and Families. PEDIATRICS, 127(4), 800-804. https:// doi.org/10.1542/peds.2011-0054

Osborne, J., Simon, S., \& Collins, S. (2003). Attitudes towards science: a review of the literature and its implications. International Journal of Science Education, 25(9), 1049-1079. https://doi.org/10.1080/0950069032000032199

Poudel, D. D., Vincent, L. M., Anzalone, C., Huner, J., Wollard, D., Clement, T., ... Blakewood, G. (2005). Hands-On Activities and Challenge Tests in Agricultural and Environmental Education. Journal of Environmental Education, 36(4), 10-22.

Raat, J. H., \& de Vries, M. J. (1986). What do girls and boys think of technology?

Raat, J. H., de Klerk Wolters, F., \& de Vries, M. J. (1989). Pupils' Attitude Towards Technology. Journal of Technology Education, 1(1), 4.

Randler, C., Baumgärtner, S., Eisele, H., \& Kienzle, W. (2007). Learning at Workstations in the Zoo: A Controlled Evaluation of Cognitive and Affective Outcomes. Visitor Studies, 10(2), 205-216. https:/ / doi.org/10.1080/10645570701585343

Rennie, L. J., \& Treagust, D. F. (1989). Measuring students attitudes and perceptions about technology: A multidimensional concept. In Intergovernmental Panel on Climate Change (Ed.), Research in Science Educationsearch (Vol. 19, pp. 221-230). Cambridge: Cambridge University Press. https://doi.org/10.1017/CBO9781107415324.004

Renninger, K. A. (2015). The Power of Interest for Motivation and Engagement. https://doi.org/10.4324/9781315771045

Rohaan, E. J., Taconis, R., \& Jochems, W. M. G. (2010). Reviewing the relations between teachers' knowledge and pupils' attitude in the field of primary technology education. International Journal of Technology and Design Education. https://doi.org/10.1007/s10798-008-9055-7

Ryan, R., \& Deci, E. (2000). Self-determination theory and the facilitation of intrinsic motivation. American Psychologist, 55(1), 68-78. https://doi.org/10.1037/0003066X.55.1.68

Sattler, S., \& Bogner, F. X. (2016). Short- and long-term outreach at the zoo: cognitive 
learning about marine ecological and conservational issues. Environmental Education Research, 4622, 1-17. https://doi.org/10.1080/13504622.2016.1144173

Schmid, S., \& Bogner, F. X. (2015). Does inquiry-learning support long-term retention of knowledge? International Journal of Learning, Teaching and Educational Research, $10(4), 51-70$.

Simpson, R. D., \& Oliver, J. S. (1990). A Summary of Major Influences on Attitude Toward and Achievement in Science Among Adolescent Students. Science Education, 74(1), 1-18. https:// doi.org/10.1002/sce.3730740102

Speering, W., \& Rennie, L. (1996). Students' perceptions about science: The impact of transition from primary to secondary school. Research in Science Education, 26(3), 283-298. https://doi.org/10.1007/BF02356940

Steele, J., James, J. B., \& Barnett, R. C. (2002). Learning in a Man'S World: Examining the Perceptions of Undergraduate Women in Male-Dominated Academic Areas. Psychology of Women Quarterly, 26(1), 46-50. https://doi.org/10.1111/14716402.00042

Weinburgh, M. (1995). Gender Differences in Student Attitudes Toward Science - a Metaanalysis of the Literature From 1970 To 1991. Journal of Research in Science Teaching, 32(4), 387-398. https://doi.org/10.1002/tea.3660320407

Weinburgh, M. (2000). Gender, Ethnicity and Grade Level as Predictors of Middle School Students ' Attitudes toward Science. https://doi.org/ED442662

Wigfield, A. (1996). Development between the ages of 11 and 25. Handbook of Educational Psychology, 148.

Wolters, F. de K. (1989). A PATT Study Among 10 to 12-Year-Old Students in the Netherlands. Journal of Technology Education, 1(1). https://doi.org/10.21061/jte.v1i1.a.4

Zeyer, A. (2010). Motivation to Learn Science and Cognitive Style. Eurasia Journal of Mathematics Science \& Technology Education, 6(2), 121-128.

Zeyer, A., \& Wolf, S. (2010). Is There a Relationship between Brain Type, Sex and Motivation to Learn Science? International Journal of Science Education, 32(16), 2217-2233. https://doi.org/10.1080/09500690903585184 